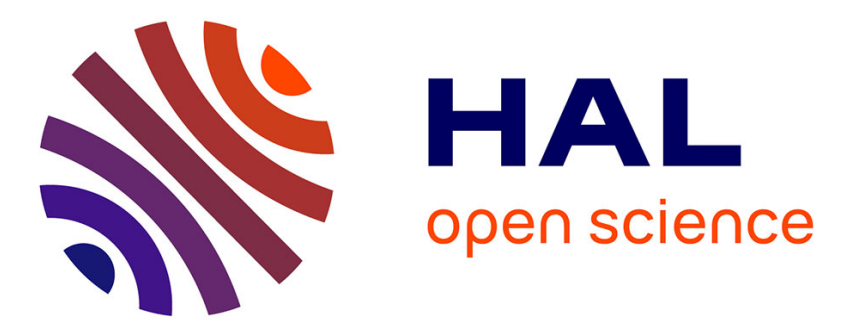

\title{
Near real time detection of hot spots on Meteosat Second Generation images: from forest fires to volcanic eruptions
}

Laurent Beaudoin, Antoine Gademer, Ahmed Amir, Loïca Avanthey, Vincent Germain, Alexandre Pocheau

\section{To cite this version:}

Laurent Beaudoin, Antoine Gademer, Ahmed Amir, Loïca Avanthey, Vincent Germain, et al.. Near real time detection of hot spots on Meteosat Second Generation images: from forest fires to volcanic eruptions. IEEE International Geoscience \& Remote Sensing Symposium, Jul 2007, Barcelona, Spain. 10.1109/IGARSS.2007.4423305 . hal-01131966

\section{HAL Id: hal-01131966 https://hal.science/hal-01131966}

Submitted on 16 Mar 2015

HAL is a multi-disciplinary open access archive for the deposit and dissemination of scientific research documents, whether they are published or not. The documents may come from teaching and research institutions in France or abroad, or from public or private research centers.
L'archive ouverte pluridisciplinaire HAL, est destinée au dépôt et à la diffusion de documents scientifiques de niveau recherche, publiés ou non, émanant des établissements d'enseignement et de recherche français ou étrangers, des laboratoires publics ou privés. 


\title{
Near real time detection of hot spots on Meteosat Second Generation images : from forest fires to volcanic eruptions
}

\author{
Laurent Beaudoin*, Antoine Gademer*, Ahmed Amir ${ }^{\dagger}$, Loïca Avanthey*, Vincent Germain*, Alexandre Pocheau* \\ *Pôle Acquisition et Traitements des Images et des Signaux (ATIS) \\ École Supérieure d'Informatique d'Électronique et d'Automatique (esiea), France, Email: beaudoin@esiea.fr \\ ${ }^{\dagger}$ Laboratoire de Géophysique de l’Environnement et de Télédétection (LGET) \\ Institut et Observatoire de Géopghysique d'Antanarivo, Madagascar
}

\begin{abstract}
In the 2005 IGARSS' symposium, we presented the setting up of a data receiving station for METEOSAT SECOND GENERATION (MSG) satellites by undergraduates and we emphasized the pedagogical interest of the project. The experience has been successfully pursued by developing with the undergraduates involved the exploitation of the data received and its promotion. Among the different activities implemented in this context, we discuss in this article the work concerning the hot spots detection in near real time on MSG images. This approach, beyond the technical and pedagogical aspects, allows the future engineers to be involved in very important issues such as global warming and natural disasters.

In order to define the forest fire detection algorithms adapted to MSG data, we start by describing the physical properties that lead us to identify the more efficient spectral bands available in MSG. Then, we deal with the different algorithms developed and the accuracy and efficiency of the detection compared with other published results.

Sometimes, we observed very localised and motionless fires during several days or even several weeks. Looking at more precise scales, we realized that these anomalies are mostly localised on active volcanoes. In order to validate the hypothesis that we really detect volcanic eruptions, we focused our attention on a very specific volcano called Karthala, Grand Comore Island, Indian Ocean. Comparing our results with ground data, we observe a very good detection of the eruption's activity from the start to the end with almost a quarter hour accuracy.
\end{abstract}

\section{Context OF The STUdY}

\section{A. About us}

The Ecole Supérieure d'Informatique d'Électronique et d'Automatique (esiea) is a French engineering school and its main teaching topics are Electronics and Computer Sciences. esiea encourages its students to work on original and practical projects that efficiently complete their more classical and theoretical course. There is a wide range of possible subjects (from hardware to sofware ones) and some of them are connected with research laboratories of the School. This article presents one of these projects and deals with near real time detection of hot spots on Meteosat Second Generation images. The research department involved in this work is the one dedicated to image and signal processing (Acquisition et Traitement des Images et du Signal - ATIS dept.).

\section{B. Hot spot detection}

Life on Earth strongly depends on various parameters. One of them is the composition of the gases in the atmosphere. Atmospheric gases result from various and complex processes (photosynthesis, respiration decay ...). Biomass burning, i.e. burning of world's vegetation including forest, savannas and agricultural lands, impacts Earth's atmosphere and biosphere with short and long term effects [1]. The main interactions concern [2] :

- the modification by smoke aerosols of the transparency of the atmosphere and the reflectivity and the emissivity of the Earth's surface that therefore changes the global energy budget [3], [4],

- the alteration of landcover that leads to changes in the hydrological cycle,

- changes the biogeochemical cycling of compounds from the biosphere to the atmosphere [5]. Biomass burning contributes in fact to about $40 \%$ of gross carbon dioxide and $38 \%$ of tropospheric ozone for example [6]

A part of this burning is natural and essential to revitalize some ecosystems [7]. The rest, which represents the vast majority of the burning, results from human activities and has increased significantly over the last century [8]. It is supposed to have a key role in global warning. The main contribution to burning biomass comes from the savannas. Therefore, Africa becomes the "burn center" of the world because two-thirds of the Earth's savannas are located on this continent.

To understand long term effects of fires on the climate and the environment, it is fundamental to know the spatial and temporal distribution of fire on a global scale, and only spatial remote sensing technologies can be applied with efficiency at reasonable cost [9]. In fact, there is no ideal sensor/platform. Each sensor/satellite has its own advantages and disavantages in fire monitoring, depending on spatial, spectral and temporal possibilities. The polar ones for example have a good spatial resolution but long revisiting time. The most used sensor for fire monitoring is AVHRR for Advances Very High Resolution Radiometer [10]. The geostationary ones have a degraded spatial resolution but a very high temporal resolution fully 


\begin{tabular}{|c|l|}
\hline spectral channel $(\mu m)$ & $\begin{array}{l}0.6,0.8,1.6,3.9,6.2,7.3,8.7,9.7,10.8, \\
12.0,13.4\end{array}$ \\
\hline sampling distance $(\mathrm{km})$ & $1 \times 1$ (HRV channel) $3 \times 3$ otherwhise \\
\hline radiometry depth & 10 bits per pixel \\
\hline image size & $\begin{array}{l}11136 \times 5568 \text { (HRV channel), } 3712 \times 3712 \\
\text { otherwise }\end{array}$ \\
\hline time sampling & 15 minutes \\
\hline
\end{tabular}

TABLE I

MAIN CHARACTERISTICS OF THE MSG DATA (HRV CHANNEL FOR HIGH RESOLUTION VISIBLE CHANNEL)

compatible with near real time monitoring [11]. In this article, we will use geostionary data.

Despite the fact that environmental issues are not the kernel of our teaching, it is essential for esiea to heighten its students' awareness of them, as they will later be in positions of high responsibilities. The work presented in this article uses satellite data received at esiea and detailled in section I-C. Because of their high temporal availability, of their well adapted spectral bands and because these data are centered on Africa, they fit particularly well with the detection and the monitoring of burning biomass which apears on these data like hot spots.

Hot spots (like forests fire seen from space for example) are very specific events that emit a lot of energy (i.e. that have a high temperature or high radiance emission). Specific events means for us events that have a spatial extent of one or only a few pixels. In other words, this kind of events have a great radiometric difference with their neighbours and specific spectral behaviours. So, the objective of the students was to capitalize on these specificities to develop a real time detection algorithm.

\section{The data}

The data used in this work are Meteosat Second Generation images that we received directly from the satellite. The lowcost receiving station has been developed by a previous generation of students and this work has already been presented in the 2005 IGARSS Symposium [12]. So, the present work is in fact a next step of this pedagogical experience.

In table I, you will find the main characteristics of the data [13]. Obviously, as Meteosat Second Generation (MSG) is a geostationary satellite, it is particularly well adapted for near real time applications.

\section{Algorithm}

\section{A. The physical phenomenon}

A combustion process has short time and mid time effects [14]. Short time effects concern the emission of heat and smoke. The char residue left on the surface and the modified vegetation structure are mid time effects. In our case, we want to take advantage of the near real time capacity of MSG, that is why we focus on the major short time effect : hot spot emited by active fire.

The typical temperature of a flame is about $1000^{\circ} \mathrm{K}$ and the one of smoldering combustion is $600^{\circ} \mathrm{K}$ [15]. The peak emission of radiance corresponding to these effects would be located between $3 \mu \mathrm{m}$ and $5 \mu \mathrm{m}$ according to Wien's displacement law. To give a comparison, a surface with a temperature of $290^{\circ} \mathrm{K}\left(17^{\circ} \mathrm{C}\right)$ has a peak of radiance at about $10 \mu \mathrm{m}$.

\section{B. Four generations of algorithms}

There are currently four major families of active fire detection algorithms but all are built upon this ability of the $3.9 \mu \mathrm{m}$ channel to detect the rapid increase of temperature produced by the active fire [10].

Considering the strong correlation between the image high values and the observed fire, older algorithms used to be simple single-channel threshold methods with coarse but satisfying visual results. Nevertheless validation of the algorithms by fine observation of the results shows a lot of false alarms (pixel detected as fires but which are not) due to specular reflection on clouds, bare ground or open water. It is to be noticed that most of the sensors, which were not built for fire monitoring, present low saturation value $\left(350^{\circ} \mathrm{K}\right.$ for $3.9 \mu \mathrm{m}$ MSG channel) and thus do not allow fine discrimination.

To reduce the number of these false alarms, the second generation of algorithms takes advantage of the full multispectral potential of the satellites sensors. These multi-channel threshold algorithms try to sort the pixels between fire and non-fire classes by analysing the spectral signature of the observed surface. Generating or using clouds masks, land use, and ancillary data they progressively eliminate the false alarms without suppressing too many of the real fire signals. The principal difficulty of these algorithms is the choice of the threshold values: indeed most approaches are datadriven and only work for regional data. Thence, you can find accurate algorithms for boreal forest, for tropical forest, etc. or global approaches with approximative results on every type of vegetation. Validation and cross-comparison of these algorithms is therefore a necessary but hard task [10]. The result of this validation shows obvious improvement since first generation but also the limitation of the model: masks cannot fit the ground data and the transition zones are a frequent source of misclassification: observations must take into account the spatial distribution of the pixels.

The third generation of algorithms emerges from the previous conclusions and makes the analysis of the spatial contextual information contained by the satellite images the heart of the fire detection algorithms. Fires are not only considered by their spectral signature but also by their neighbourhood. The thresholds are here deduced from statistical calculations and not from experimental tuning with a global detection goal. As for validation, these third generation algorithms show good results with very few false alarms but have two drawbacks: firstly, with their global approach they tend to miss the small fires and thus are less useful for early detection and operational response and secondly they still do not fully take into account the effect of sun reflections which depend in the majority of cases on the reflectivity of the objects.

Surface reflectivity is not easy to determine as it is dependent on the physical nature of all the components of the pixel. Futhermore, classic satellite resolution implies that each 
pixel contains a wide range of elements, but this composition may change in time. The next generation makes the bet of calculating the reflectivity by observing long time series. Knowing this mean reflectivity we can calculate the expected brilliance temperature and analyse the variation as potential fire. Another exploratory approach with time-series tries to use change detection to detect the onset of the fire. These approaches are still in progress and have not yet been fully validated.

\section{Our algorithm}

Our algorithm belongs to contextual fire detection algorithm generation. Started as student work the approach selected is quite original: our contextual approach is not based on statistical computation but on morphological mathematics. In this way, we hope to avoid some of the threshold determination problems.

Morphological filters are common image processing tools and therefore we will not explain the theory. The top-hat filter used here is a difference between the original and a filtered image with the opening morphological operator. The opening filter suppresses all objects of the original signal smaller than the morphological element size and therefore the top-hat filter focuses attention on all the small elements.

The filtered image is considered as a mask for the potential fire, but as in the other algorithms we have to set some tests to discriminate the non-fire hot spots. Our primary test is to avoid water pixels with a sea/land mask.

As a second test we use hot surface test analysing the difference between channel $3.9 \mu \mathrm{m}$ and the $10.8 \mu \mathrm{m}$. As shown in [10] due to the non-linearity of the Planck function, this test is mostly correlated to the thermal homogeneity of the pixel: in the presence of fire the thermal homogeneity drops and the difference of channel jumps. The coarse spatial resolution of MSG validates this test. The last test yet implemented is the cloud mask. Imported from the IBGP cloud test on AVHRR data, it uses the radiance of 0.6 and $0.8 \mu \mathrm{m}$ visible spectrum channels and the brilliance temperature of $12 \mu \mathrm{m}$ infrared channels. In the mid term we are planning to use full cloud information from SAFNWC [16] delivered by EUMETCAST along the MSG data.

\section{RESULTS AND DISCUSSION}

The main difficulty to validate our results lies in the comparason with ground data. A practical approach could be the use of available data produced by the other algorithms.

\section{A. Available fire monitoring products}

We can found fire map products for almost each algorithm published. Among them, some of the most popular are :

- for geostationary data, ABBA (GOES) and FIR (MSG)

- for polar data, FIMMA (AVHHR) and MODIS Rapid Response System.

The data are usually available in different formats : ascii, GIS products or image. The datasets vary from 15 minutes
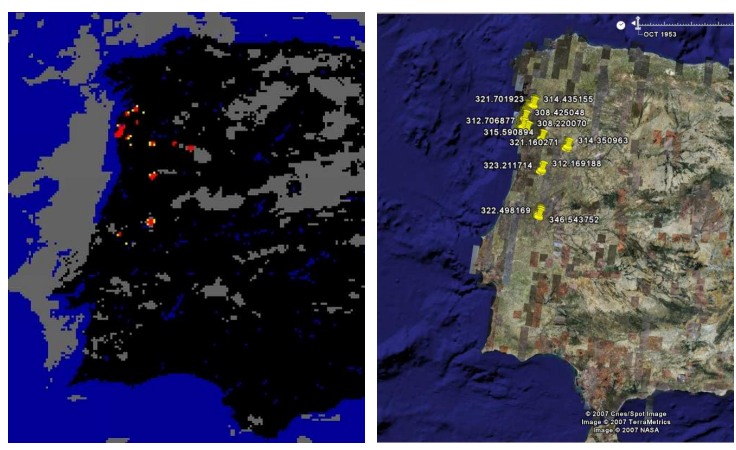

Fig. 1. Result of the FIR algorithm (on the left) and our result (on the right) on Portugal during the summer 2005.

frequency for the last 24 hours to nine days cumulative results for the past 6 years.

These results tend to be very inhomogeneous and strongly dependant of the chosen set of parameters of the algorithms. It is the reason why direct comparison is difficult as no algorithm can be taken as absolute reference.

Nevertheless, the visual checking of the results with available fire monitoring products are coherent. Figure 1 shows for example the result obtained by the FIR algorithm (on the left) and our result (on the right) on Portugal during the summer 2005.

Then, a temporal checking has been done over Africa. The most unexpected observation was the duration of some fires (until several days). These exceptionnal situations always occur on erupting volcanoes. So, the work created for the monitoring of biomass burning could be extended to the monitoring of volcanic eruptions.

\section{B. Monitoring volcanic eruptions: the Karthala's eruption example}

Karthala volcano, an active basaltic shield, forms with the older La Grille Massif the island of Grande-Comore [17], [18]. It has a summit caldera and two main rift zones [19]. The center of the caldera has a pit crater $290 \mathrm{~m}$ deep named "Choungou Chahale". The Karthala volcano forms the southern two-thirds of the Grande Comore Island in the Indian Ocean between latitude $11-13^{\circ} \mathrm{S}$ and longitude $43-46^{\circ} \mathrm{E}$. This volcano was explored for the first time by Dr. Kresten in 1883 but there is little knowledge on the history, the structure, geology, the geophysics and the geodynamic context of the island. GrandeComore is the youngest island of the Comoros archipelago which has four islands. A dating of the lava of low slopes of the top of the volcano by [18] indicated a date more recent than 130.000 years.

The eruptions of the volcano have been indexed since 1828 . More than twenty eruptions have been recorded since the 19th century from both summit and flank vents [20]. The Karthala eruptive style is mostly effusive, however phreatic or phreato-magmatic explosions have occurred in 1918, 1948, 1952, 1991 and 2005 [21]. The one which took place on July 11,1991 was purely phreatic and formed a new crater $(250 \mathrm{~m}$ 


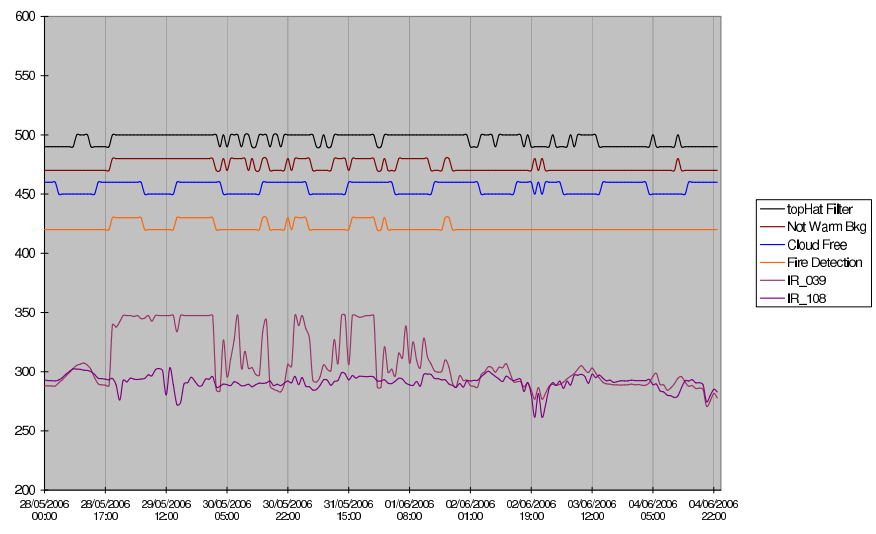

Fig. 2. Observation of the Karthala eruption by MSG. In the low part of the chart the 3.9 and 10.8 mum channels. In the higher part the tests of the fire algorithm.

in diameter, 43m deep). In the bottom of Choungou-Chahale, which was partly filled by a lake. The eruption of November 2005 released ashes which covered the entire island. Most of the population was deprived of drinking water for a few days.

The eruption dealt with in this article is supposed to have begun on May 28, 2006 between 6:30pm and 8:00pm. It created a lake of lava in the crater Choungou Chahale. The Lake of lava apparently remained for five days. The flying over the crater on the fifth day of the eruption confirmed the cooling of the lake of lava.

This eruption was not preceded by seismic activities. It was thus a surprise for the inhabitants of the island. The observatory of Karthala which had two seismic stations working at the time of the eruption detected no abnormal activity before the eruption and the formation of the lake of lava within the crater. It was not the case of the last eruption of January 13, 2007 which had intense seismicity before and during the eruption. The latter reformed a lake of lava in the crater Choungou Chahalé.

Figure 2 shows the response of the algorithm for the pixels concerned by the eruption in orange. Above are represented the tests' responses of the components of the algorithm. Below the spectral response in 3.9 and $10.8 \mathrm{mum}$ channels. As you can see, there is a good correlation between the real start of the eruption and the hot spot detection. But we can see that the cloud test creates some lack of detection despite the fact that the eruption is still ongoing. Visual checking confirms the presence of the cloud, but the temperature of the eruption is so high that it nevertheless satures the pixel and should be detected. We conclued that classic fire detection algorithm has to be adapted to include the full detection of the volcanoes' eruptions.

\section{CONCLUSION}

In this article, we have presented a student work dedicated to active fires' detection. This work follows through the previous pedagogical experience presented in 2005 [12]. The first results are encouraging and multiple ways of improvement are planned. We have also presented another application for these algorithm with the volcano eruption detection and survey. Nevertheless, we have shown that full investigation will need some adaptations in the algorithms.

\section{ACKNOWLEDGMENT}

The authors would like to thank Eumetsat and Météofrance organisations, Groupe De Recherche Meteosat Seconde Generation (GDR MSG) and Jean-Claude Bergès.

\section{REFERENCES}

[1] P. Crutzen, L. Heidt, J. Krasnec, W. Pollock, and W. Seiler, "Biomass burning as a source of atmospheric gases $\mathrm{CO}, \mathrm{H} 2, \mathrm{~N} 2 \mathrm{O}, \mathrm{NO}, \mathrm{CH} 3 \mathrm{CL}$ and COS," Nature, vol. 282, pp. 253-256, 1979.

[2] J. S. Levine, Biomass Burning and Global Change. The MIT Press, 1996.

[3] Y. Kaufman and R. Fraser, "The effect of smoke particles on clouds and climate forcing," Science, vol. 277, pp. 1636-1639, 1997.

[4] Z. Li, "Influence of absorbing aerosols on the solar surface radiation budget," Journal of Climate, vol. 11, pp. 5-17, 1998.

[5] R. Houghton, "Biomass burning from the perspective of the global carbon cycle," in Global Biomass Burning: Atmospheric, Climatic, and Biospheric Implications, J. Levine, Ed. The MIT Press, 1991.

[6] J. S. Levine, W. R. Cofer, D. R. Cahoon, and E. L. Winstead, "1995: Biomass burning: A driver for global change," Environmental Science and Technology, vol. 29, no. 3, pp. 120-125, 1995.

[7] F. Bonn, Précis de télédétection. AUPELF-Presses de l'Université du Québec, 1996, vol. 2, ch. Télédétection des forêts.

[8] M. Andrea, "Biomass burning: its history, use and distribution and its impact on environmental quality and global change," in Global Biomass Burning: Atmospheric, Climatic, and Biospheric Implications, J. Levine, Ed. The MIT Press, 1991.

[9] C. Justice, J. Malingreau, and A. Setzer, "Remote sensing of fire: potential and limitations," in Fire in the environment: the ecological, atmospheric and climatic importance of vegetation fires. John Wiley, 1993, pp. 77-88.

[10] Z. Li, Y. Kaufman, C. Ithoku, R. Fraser, A. Trishchenko, L. Gilgil, J. Jin, and X. Yu, "A review of avhrr-based fire active fire detection algorithm: Principles, limitations, and recommendations," in Global and Regional Vegetation Fire Monitoring from Space, 2001.

[11] E. Prins, D. McNamara, and C. Schmidt, "Global geostationary fire monitoring system," in Conference on Satellite Meteorology and Oceanography, 2004.

[12] L.Beaudoin, L.-A. Chabardès, J. Cornebise, C. Dufour, K. Florczak, F. Gachot, and P. Schott, "A Meteosat Second Generation receiving, processing and storing images system developed by engineer students," in IGARSS, 2005.

[13] MSG system overview-TD07, EUMETSAT, 2001.

[14] J. Pereira and Y. Govaerts, "Potential fire applications from MSG/SEVIRI observations," EUMETSAT, Tech. Rep. TM07, 2001.

[15] J. Lobert and J. Warnatz, "Emission from the combustion process in vegetation," in Fire in the environment: the ecological, atmospheric and climatic importance of vegetation fires. John Wiley, 1993.

[16] http://nwcsaf.inm.es.

[17] A. Lacroix, Le volcan actif de l'ile de la Réunion et celui de la GrandeComore. Gauthier-Villars, 1938.

[18] P. Bachèlery and J. Coudray, "Carte volcano-tectonique de la GrandeComore ngazidja.au 1/50000 avec notice explicative." Ed. Mission Française de cooperation aux Comores., 1993.

[19] P. Bachèlery, D. B. Ali, F. Desgrolard, J. Toutain, J. Coudray, J. Cheminée, and J. Klein, "L'éruption phréatique du volcan karthala (grande-comore) en juillet 1991 : première crise sismo-volcanique suivie depuis l'implantation d'un réseau de surveillance," C. R. Acad. Sci. Paris, vol. 320, no. Série IIa, 1995.

[20] http://www.volcano.si.edu, "Global volcanism program."

[21] C. Savin, M. Ritz, J. Join, and P. Bachèlery, "Hydrothermal system mapped by csamt method on karthala volcano, grande-comore island (indian ocean)," Journal of applied Geophysics, vol. 28, no. 3, pp. 143$152,2002$. 